\title{
Correction to: Undifferentiated Shock
}

\author{
Russell G. Day and Sage P. Whitmore
}

\section{Correction to: R. C. Hyzy, J. McSparron (eds.), Evidence-Based Critical Care, https://doi.org/10.1007/978-3-030-26710-0_3}

Figures 3.1, 3.2, 3.3, 3.4 that were incorrectly placed have now been updated with the correct figures.

Fig. 3.1 Shock types and examples. $R V$ right ventricle, $P T X$ pneumothorax, $P E$ pulmonary embolism, $H T N$ hypertension, $L V$ left ventricle, SIRS systemic inflammatory response syndrome, GI gastrointestinal

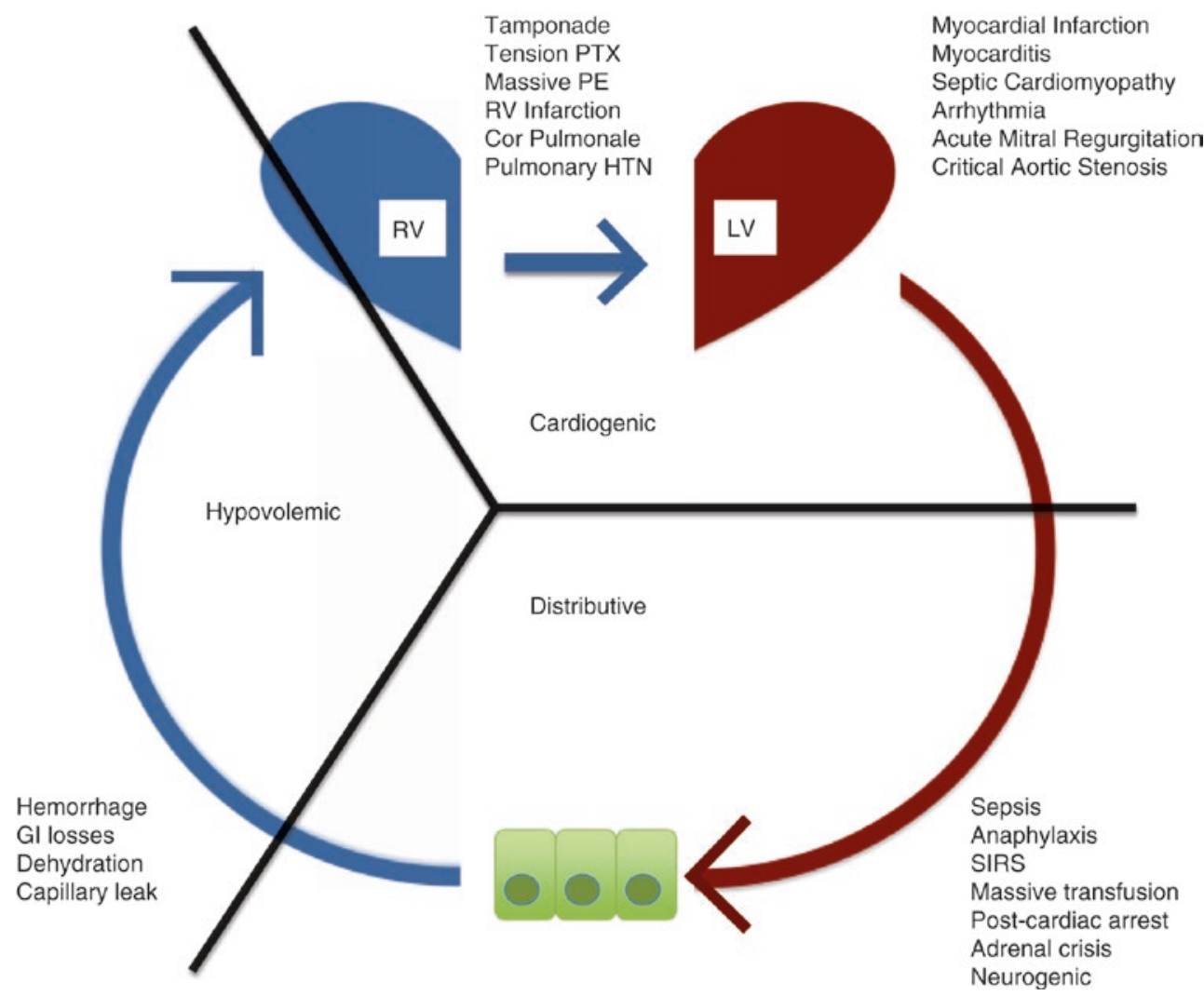

The updated online version of this chapter can be found at https://doi.org/10.1007/978-3-030-26710-0_3 
Fig. 3.2 Physiologic determinants of right heart preload. $P_{M S}$ mean systemic pressure, $R A P$ right atrial pressure, $R$ resistance, $R V$ right ventricle

\section{Right heart preload $\approx\left(P_{M S}-R A P\right) / R$}

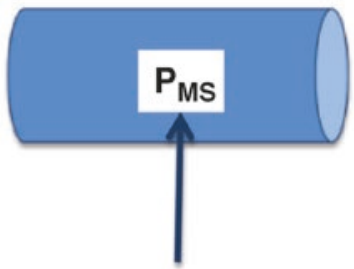

$\underline{\text { Venules, Veins }}$

Increased by:

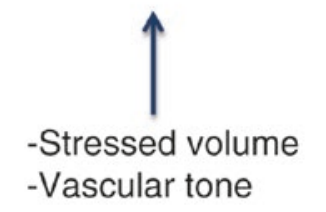

-Stressed volume

-Vascular tone

Vena cava

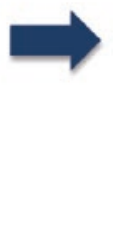

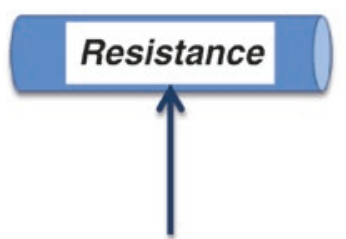

Increased by:

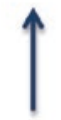

-Venoconstriction -Blood viscocity

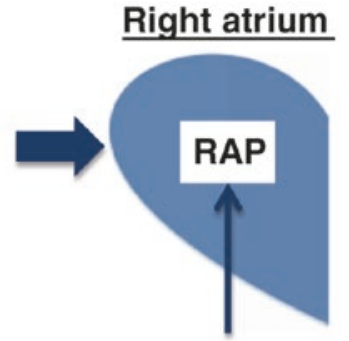

Increased by:

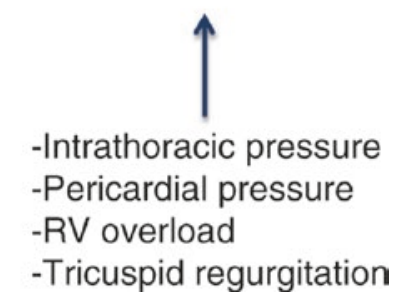

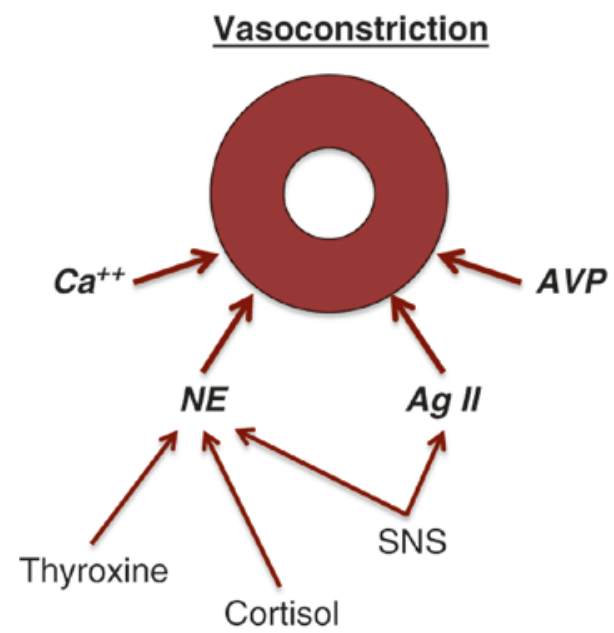

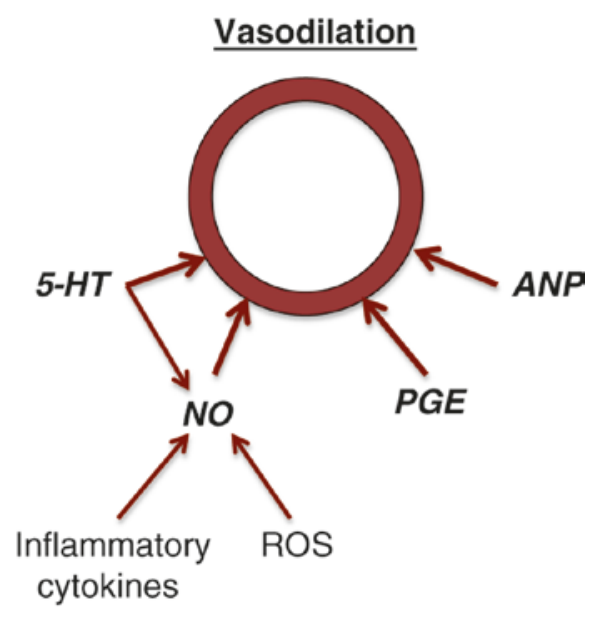

Fig. 3.3 Physiologic determinants of vascular tone. $\mathrm{Ca}^{2+}$ calcium, $\mathrm{NE}$ norepinephrine, $\mathrm{Ag}$ II angiotensin, $\mathrm{AVP}$ arginine vasopressin, $S N S$ sympathetic nervous system, 5-HT serotonin, $N O$ nitric oxide, $P G E$ prostaglandin, $A N P$ atrial natriuretic peptide, $R O S$ reactive oxygen species 


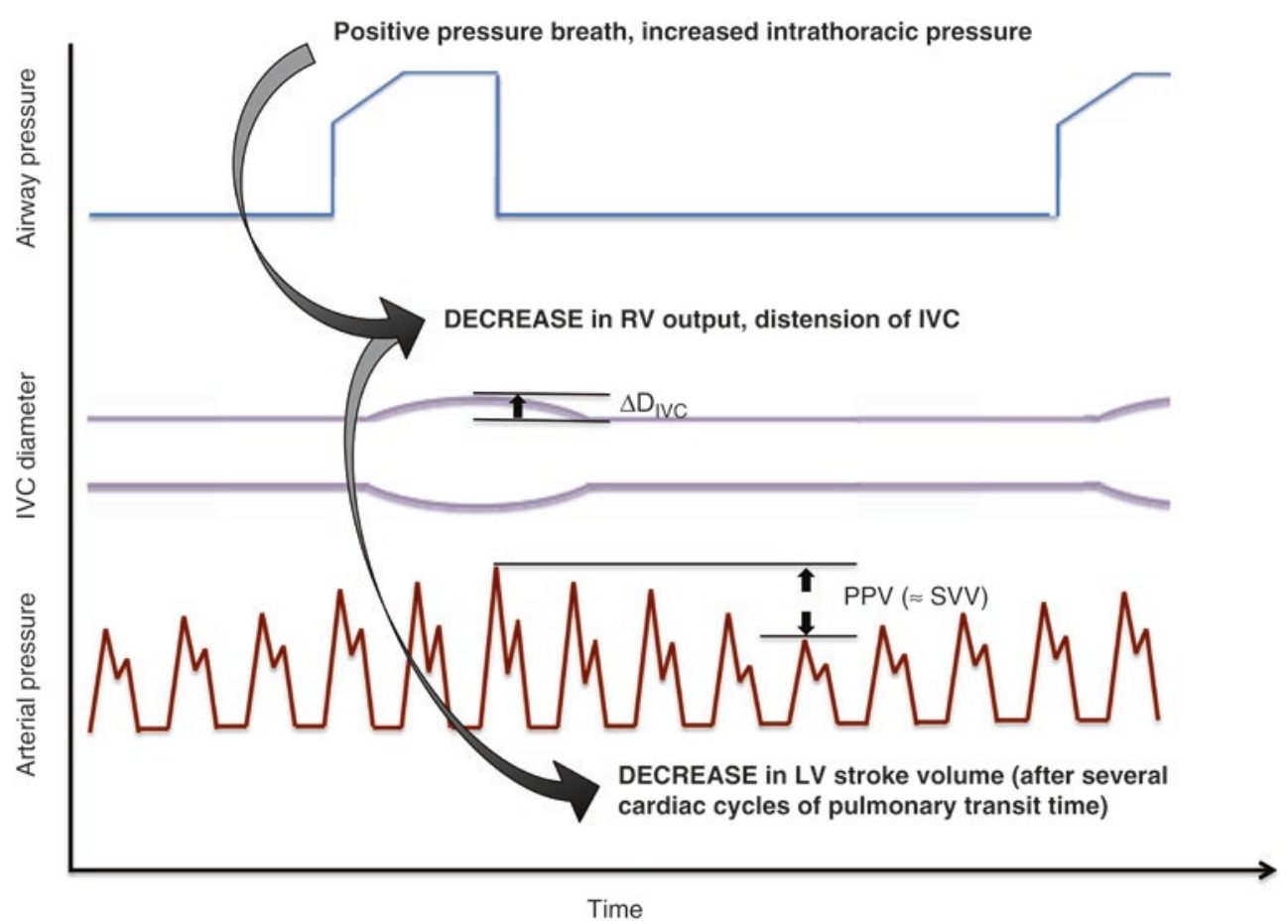

Fig. 3.4 Effects of positive pressure ventilation on IVC diameter and stroke volume variation. $R V$ right ventricle, $I V C$ inferior vena cava, $\Delta D_{I V C}$ change in diameter of IVC, $P P V$ pulse pressure variation, $S V V$ stroke volume variation, $L V$ left ventricle 